doi:10.17659/01.2020.0036

Journal of Case Reports 2020;10(3):136-138

\title{
Simultaneous Percutaneous Transcatheter Closure of ASD and VSD
}

\author{
Harsha Basappa ${ }^{1}$, Sachin Rao ${ }^{1}$, Srinidhi Hegde ${ }^{1}$, C. N. Manjunath ${ }^{2}$ \\ ${ }^{1}$ Department of Cardiology, Sri Jayadeva Institute of Cardiovascular Sciences and Research, Mysore; ${ }^{2}$ Department of Cardiology, \\ SJICSR, Bangalore, Karnataka, India.
}

\section{Corresponding Author:}

Dr. Sachin Rao

Email: rao.sachin86@gmail.com

This is an Open Access article distributed under the terms of the Creative Commons Attribution License (creativecommons.org) licenses/by/3.0).

Received

Accepted

Published

March 31, 2020

June 27,2020

July 5,2020

\begin{abstract}
Background: The most common types of congenital heart defects (CHDs) are septal defects. However, combined atrial septal defect (ASD) and ventricular septal defect (VSD) are infrequently reported. Trans-catheter interventions serve as a suitable alternative to surgery. However simultaneous closure of ASD and VSD in a single patient under single procedure is rarely reported. We report a case of successful simultaneous closure of both septal defects at the same session. Case Report: The patient is a 22 year old male with $12 \mathrm{~mm}$ ostium secundum ASD and $8 \mathrm{~mm}$ subaortic VSD noted on transthoracic echocardiography with significant shunt. VSD was closed from arterial route by forming an arterio-ventricular loop. Subsequently ASD was closed. Postprocedure was uneventful. Conclusion: Simultaneous percutaneous closure of combined septal defects is a suitable alternative to surgical closure. We report such a rare case of combined closure which sets an example for future endeavors.
\end{abstract}

Keywords: Congenital Heart Defects, Dyspnea, Fatigue, Echocardiography, Heart Septal Defects.

\section{Introduction}

Percutaneous closure of atrial septal defect (ASD) and ventricular septal defect (VSD) are well described. However simultaneous closure of ASD and VSD in a single patient is very rarely reported. We report a case of successful simultaneous closure of both the septal defects at the same session. This case highlights the fact that simultaneous percutaneous closure of septal defect saves the patient from surgical closure and its associated mortality and morbidity.

\section{Case Report}

A 22 year old male patient presented with dyspnea on exertion, fatigue since few months. Physical examination showed sinus tachycardia and ejection systolic murmur in pulmonary area, loud P2. ECG showed right bundle branch block, sinus tachycardia. Two-dimensional trans-thoracic echocardiography showed presence of $12 \mathrm{~mm}$ ostium secundum ASD and $8 \mathrm{~mm}$ sub-aortic VSD and mildly dilated right sided chambers with pulmonary artery systolic pressure of $60 \mathrm{mmHg}$. Moderate pulmonary hypertension was noted. Calculated Qp/Qs was 2.4. Cardiac MRI better delineated the sizes of ASD and VSD [Video 1,2]. As the left to right shunt was significant, he was posted for trans-catheter closure of ASD and VSD. VSD was first closed followed by ASD device closure. Left ventriculogram using a $5 \mathrm{~F}$ pigtail showed a $7 \mathrm{~mm}$ VSD [Fig.1]. It was closed with 8/10 mm Lifetech PDA occluder from arterial route by forming an arterio-ventricular loop [Fig.2]. Subsequently ASD was closed with 14 mm Lifetech ASD occluder device [Fig.3]. Postprocedure was uneventful. ECG showed sinus rhythm. The patient was discharged with dual antiplatelets. 


\section{Discussion}

Septal defects are the most common types of congenital heart defects (CHDs) with the exception of bicuspid aortic valve. An unrepaired ASD can lead to left-to-right shunt, secondary right ventricular volume overload, and pulmonary overcirculation. Similarly an unrepaired VSD may eventually lead to pulmonary arterial hypertension with increased pulmonary vascular resistance and Eisenmenger's physiology. Although surgical closure is considered mainstream, in recent years, there has been shift towards trans-catheter approach for suitable lesions.

Combined defects are infrequently found especially in otherwise healthy individuals. They are usually treated with surgical closure. Transcatheter interventions are suitable alternative to surgery for various heart defects. Improved hardwares and newer techniques have largely contributed to the rise of interventional procedures. Percutaneous closure of multiple congenital defects in the same patient is rarely reported. Not many case reports are available for combined transcatheter procedures. Combined procedures reduce the need for surgical closure of congenital defects and their associated mortality and morbidity. Most of the available data are with combined balloon valvuloplasty with closure of ASD, VSD and PDA [1-3]. Combined ASD and VSD device closure is reported in three case reports till now, two in infants [4,5] and one in adult [6]. This is the fourth similar case report to the best of our knowledge. There are few case reports of such combined intervention in Down syndrome [7].

\section{Conclusion}

Multiple shunts are rarely seen in a single patient. Simultaneous percutaneous closure of amenable defects avoids surgical correction and its associated complications. This case is an encouragement for future such cases for simultaneous closure.

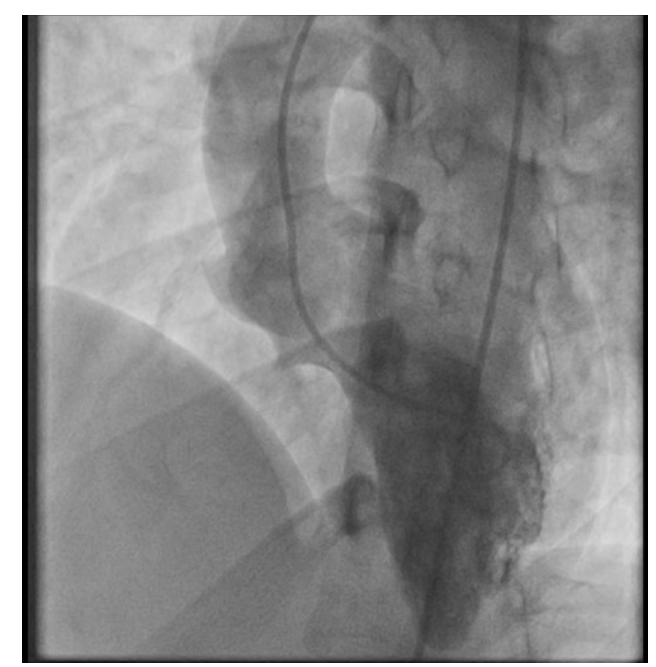

Fig.1: Left ventriculogram using a $5 F$ pigtail catheter showing a $7 \mathrm{~mm}$ subaortic VSD.

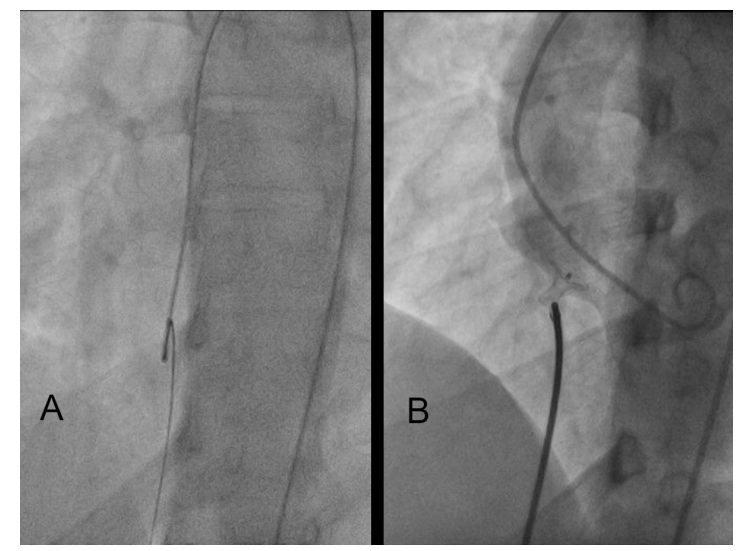

Fig.2 (a): An arterio-ventricular loop was formed by using a $5 F$ multipurpose catheter from arterial route. (b): VSD was closed with 8/10 mm Lifetech PDA occluder.

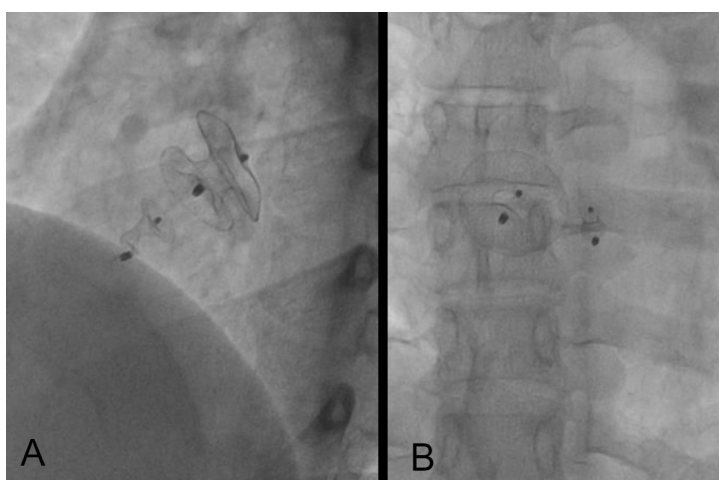

Fig.3: Final fluoroscopic image with presence of both ASD and VSD devices (a): Lateral view and (b): AP view. 
Contributors: HB, SR: manuscript writing, literature review and surgery; SH: literature review and surgery. CNM: critical inputs into the manuscript and surgery. SR will act as a study guarantor. All authors approved the final version of this manuscript and are responsible for all aspects of the study.

Funding: None; Competing interests: None stated.

\section{References}

1. Song ZY, Shu MQ, Hu HY. Clinical efficiency and safety analysis of transcatheter interventional therapy for compound congenital cardiovascular abnormalities. Clin Cardiol. 2007;30:518-521.

2. Gupta M, Juneja R, Saxena A. Simultaneous device closure of muscular ventricular septal defect and pulmonary valve balloon dilatation. Catheter Cardiovasc Interv. 2003;58:545-547.

3. Ho CL., Fu YC, Jan SL, Lin MC, Chi CS, Hwang B.
Combined transcatheter closure of atrial septal defect and patent ductus arteriosus: report of two cases. Acta Paediatr Taiwan. 2006;47:197-199.

4. Narin N, Pamukcu O, Baykan A, Sunkak S, Uzum K. Percutaneous ASD and VSD closure of 4-monthold infant in the same session. Int J Cardiovasc Acad. 2015;1:59-61.

5. Kumar V, Banerjee A, Aggarwal N, Garg S, Swamy A. Atrial and ventricular septal defects device closure in a child in one session. Indian Heart J. 2016;68:370-372.

6. Iyisoy A, Demirkol S, Celik T, Balta S. Percutaneous transcatheter closure of atrial and ventricular septal defect in the same session. Arch Turk Soc Cardiol. 2014;42:314

7. Tripathi RR. Simultaneous transcatheter device closure of ASD, VSD and PDA in an infant with Down syndrome. Interv Cardiol. 2017;10.21767/2471-8157.100069. 